\title{
A Review: Design of Active Power Filters using Soft Computing Techniques
}

\author{
Jyoti Singh Rathore ${ }^{1}$, Archana Gupta ${ }^{2}$ \\ M.Tech Student, Department of Electrical Engineering, Bhilai Institute of Technology, Durg, India ${ }^{1}$ \\ Professor, Department of Electrical Engineering, Bhilai Institute of Technology, Durg, India ${ }^{2}$
}

\begin{abstract}
Electrical power quality determines the fitness of a system. Major power quality issues nowadays are harmonics and reactive power. Non-linear loads are the main cause of introduction of harmonics in the system. To mitigate these harmonics, suitable filters are needed to be introduced in the system. Active power filter provides an effective and adjustable solution to eliminate harmonic current and compensate reactive power in an electrical power system. Its performance depends on the strategies employed and the type of controller being used in reference current generation. This paper presents a survey on using soft computing techniques and application of different control strategies in active power filter.
\end{abstract}

Keywords: Shunt active power filter (SAPF), voltage source inverter(VSI), PI controller, PID controller, fuzzy logic controller, PSO, control strategies.

\section{INTRODUCTION}

Electrical power quality is defined as maintaining the near sinusoidal waveform of power distribution bus currents and voltages as well at rated magnitude and frequency. Harmonics \& reactive power are the major causes of poor power quality nowadays. The rise of non-linear industrial loads such as rectifiers, inverters, adjustable speed drives, power converters, etc. has resulted in the problem of harmonic currents[49]. Non-linear loads create harmonics by drawing current in abrupt short pulses, rather than in a smooth sinusoidal manner. The demand from the customers for good quality of power supply is rising due to the increase of sensitive loads which is a challenging task. Reactive power is the power that supplies the stored energy in reactive elements which is generally treated as unused powers. The inductive industrial loads draw reactive power. The problem can be solved by the use of synchronous condensers, static VAR compensators etc. Harmonic is defined as a component of a periodic wave having a frequency that is an integral multiple of the fundamental power line frequency of $50 \mathrm{~Hz}$.

To deal with the above problems, filters have been introduced in the system. A filter is an electrical circuit that separates some frequencies from others within mixedfrequency signals. Filters are used to reduce harmonics and additionally compensate the reactive power[48]. Filters can be active or passive. Passive power filters are less expensive and simple in operation. The problem of resonance occurs with passive filters. Active power filters are switching mode power electronic converters, specifically designed to inject harmonic currents in equal and opposite in phase at point of common coupling (PCC). Active power filters can be current sourced that injects harmonic current or voltage sourced that injects harmonic

voltage. It can be series APF or shunt APF based on the type of connection with utility. Shunt active power filters are used generally. A voltage source converter is used as an SAPF whose gate pulses are generated using different types of control strategies, different types of controllers can also be used.

\section{SHUNT ACTIVE POWER FILTER (SAPF)}

Shunt active power filter compensates current harmonics by injecting equal and opposite harmonic current at the point of common coupling (PCC). SAPF is used for current harmonic filtering and reactive power compensation [1]. It provides the most efficient current harmonic compensation in a compact unit. SAPF can't be overloaded and is easy to retrofit. Being parallel to the load it allows for redundancy to be built in the system. It has a little loss and it is also insensitive to grid conditions. It draws current in such a way that the source current which is the sum of load current and filter current becomes sinusoidal. The principle of operation of an active power filter is to generate compensating currents into the power system for cancelling the current harmonics contained in the non-linear load current [2,41]. SAPF extracts the fundamental component from the distorted waveform using different control techniques. Fig.2.1 shows a shunt active power filter.

The reference current for shunt power active filter (SPAF) is determined by calculating the fundamental harmonic of the nonlinear load current and subtracting it from the total current which can be obtained by different methods[2]. Different control strategies have been used for reference current generation[43]. For the generation of gate pulses of 
Vol. 5, Issue 1, January 2017

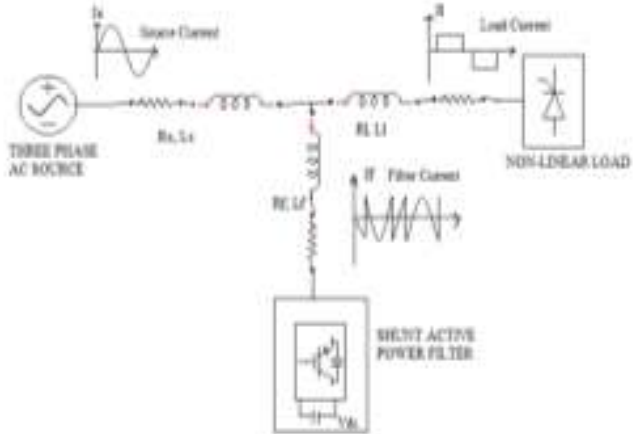

Fig. 2.1 Shunt Active Power Filter

voltage source inverter (VSI) of SAPF system, these strategies are used. The effectiveness of active power filter depends on accurate extraction of fundamental component of current waveform and fastness of control strategy which are of three types viz, synchronous reference frame theory, DC link PI control theory and instantaneous reactive power theory.

The time domain based synchronous reference frame theory used to extract reference current from distorted line current using Clarke's and Park's transformation. Clarke's Transformation equations are given by equations (1), (2) and (3) while Park's transformation equations (4), (5) and (6).
$I_{\alpha}=2 / 3 I_{a}-1 / 3 I_{b}-1 / 3 I_{c}$
$\mathrm{I}_{\beta}=1 / \sqrt{ } 3\left(\mathrm{I}_{\mathrm{b}}-\mathrm{I}_{\mathrm{c}}\right)$
$\mathrm{I}_{\gamma}=1 / 2\left(\mathrm{I}_{\mathrm{a}}+\mathrm{I}_{\mathrm{b}}+\mathrm{I}_{\mathrm{c}}\right)$
$I_{d}=\sqrt{2} / 3\left[I_{a} * \cos \theta+I_{b} * \cos (\theta-120)+I_{c} * \cos (\theta+120)\right] \ldots(4)$
$I_{q}=-\sqrt{2} / 3\left[I_{a}^{*} \sin \theta+I_{b} * \sin (\theta-120)+I_{c} * \sin (\theta+120)\right] \ldots(5)$
$\mathrm{I}_{0}=1 / \sqrt{ } 3\left(\mathrm{I}_{\mathrm{a}}+\mathrm{I}_{\mathrm{b}}+\mathrm{I}_{\mathrm{c}}\right)$

In the method of DC link PI control strategy, the amount of the main current is found by the power balance of the main voltages and current, the power converter and the load. The capacitor which is located on the DC bus of VSI is used as energy storage component for regulating voltage and delivering reactive power to the load.

Instantaneous reactive power theory uses the transformation from a three phase three wire system to two phase system. This control algorithm gives a basic way to find the reference currents for the Shunt APF system[44]. The theory is based on the Clarke's transformation which is given by:-

$I_{\alpha}=2 / 3 I_{a}-1 / 3 I_{b}-1 / 3 I_{c}$

$\mathrm{I}_{\beta}=1 / \sqrt{3}\left(\mathrm{I}_{\mathrm{b}}-\mathrm{I}_{\mathrm{c}}\right)$

$\mathrm{I}_{\gamma}=1 / 2\left(\mathrm{I}_{\mathrm{a}}+\mathrm{I}_{\mathrm{b}}+\mathrm{I}_{\mathrm{c}}\right)$

The APF needs an accurate control algorithm that provides robust performance under source and load unbalances. Better control strategy leads to better dynamic response of the system.

\section{PROBLEM FORMULATION}

In this work we have designed a shunt active power filter for a three phase system with non linear load. The filter injects the required current at the point of common coupling (PCC) and cancels out the harmonics from source current. The system consists of a three phase AC supply source, an active power filter and a non-linear load (here a diode rectifier has been used). Voltage source inverter (VSI) has been used as SAPF in this system. Since VSI has six IGBTs/Diodes, so gate pulses are needed to be generated to activate these devices and at this point the DC link PI control strategy has been used. Later on the PI controller being used is replaced by PID controller and fuzzy controller consequently [3,9]. PSO algorithm has also been used at the next stage to optimise the proportional and integral constants of PI controller[38,42,47]. Fuzzy logic and particle swarm optimisations are the two soft computing techniques that has been reviewed[50]. The value of THD before and after using SAPF in the system is observed and is found to be decreasing. Hysteresis band current has been used in the gate pulse generation system[46]. Following parametric values have been used to design the desired system.

\begin{tabular}{|l|l|}
\hline System Parameters & Values \\
\hline Source Voltage & $100 \mathrm{~V}$ \\
\hline Frequency & $50 \mathrm{~Hz}$ \\
\hline $\mathrm{R}_{\mathrm{s}}, \mathrm{L}_{\mathrm{s}}$ & $0.05 \Omega, 0.05 \mathrm{mH}$ \\
\hline $\mathrm{R}_{\mathrm{f}}, \mathrm{L}_{\mathrm{f}}$ & $20 \Omega, 15 \mathrm{mH}$ \\
\hline $\mathrm{R}_{\mathrm{l}}, \mathrm{L}_{\mathrm{l}}$ & $20 \Omega, 15 \mathrm{mH}$ \\
\hline $\mathrm{K}_{\mathrm{p}}, \mathrm{K}_{\mathrm{i}}, \mathrm{K}_{\mathrm{d}}$ & $0.2,9.32,27$ \\
\hline Reference DC voltage & $220 \mathrm{~V}$ \\
\hline
\end{tabular}

Table 3.1 System parameter specifications

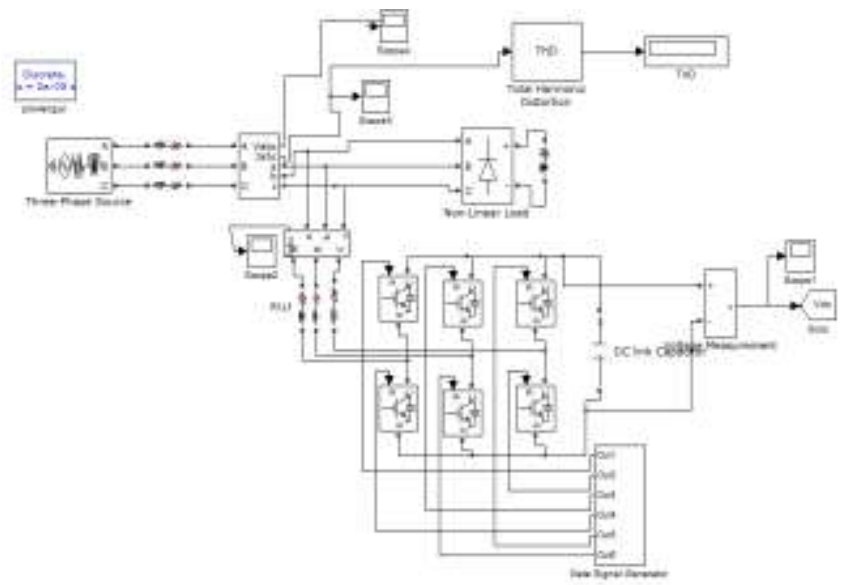

Fig 3.1 SAPF system using PI controller in MATLAB simulink

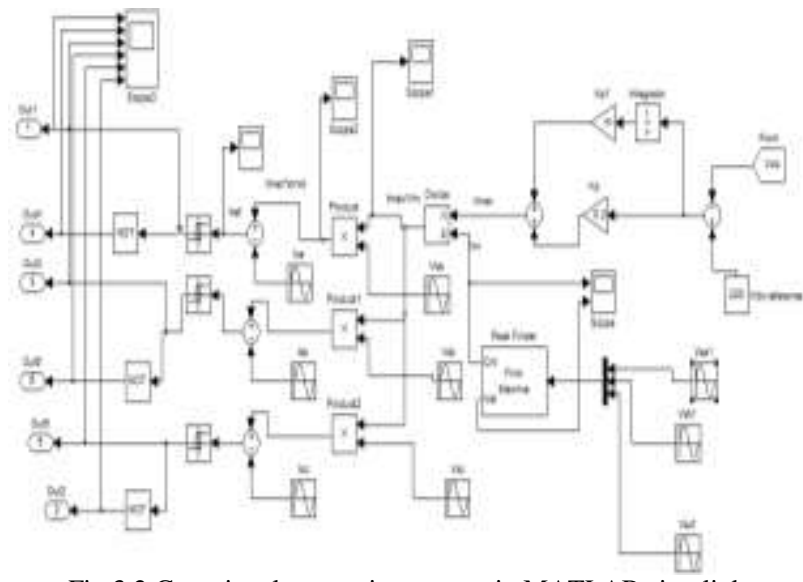

Fig.3.2 Gate signal generation system in MATLAB simulink 
Vol. 5, Issue 1, January 2017

\section{LITERATURE SURVEY}

Different types of control strategies have been used in several papers. And different outputs were obtained in each of these strategies. According to the type of control strategy used in SAPF systems, papers have been studied. Three types of control strategies is shown in fig.4.1.

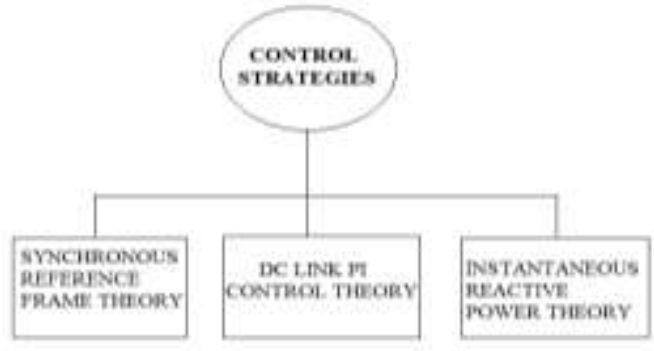

Fig. 4.1 Different types of control strategies

\section{A. Synchronous Reference Frame Theory}

Consalva et al. presented a paper in which a method for obtaining the desired reference current for voltage source converter (VSC) of the shunt active power filter (SAPF) using synchronous reference frame theory has been used. The method relies on the performance of the proportionalintegral (PI) controller for obtaining the best control performance of the SAPF. To improve the performance of the PI controller, the feedback path to the integral term is introduced to compensate the winding up phenomenon due to integrator. Using reference frame transformation, reference signals are transformed from $a-b-c$ stationery frame to $0-d-q$ rotating frame[4]. Synchronous reference frame (SRF) algorithm is developed for low voltage laboratory prototype using digital signal processor (DSP) in a paper presented by Tapankumar et al. [5]. Sunitha and Kartheek presented a paper in which using reference frame transformation, reference signals are transformed from $a-b-c$ stationery frame to $0-d-q$ rotating frame. Using the PI controller, the reference signals in the $0-\mathrm{d}-\mathrm{q}$ rotating frame are controlled to get the desired reference signals for the pulse width modulation[6]. A paper by Kakoli Bhattacharjee says that the synchronous reference frame method (SRF) is based on the fact that harmonics change their frequency in a rotating reference frame, and so they are better isolated with high pass filters [7]. Sundaram and Venugopal used synchronous reference frame algorithm to implement a three phase three level SAPF on an embedded platform[8]. A modified harmonic and reactive current detection method based on SRF theory for three-phase four-wire SAPF is proposed under distorted supply voltages condition in a paper by Xiangshun et al. [9]. A paper by Alberto Pigazo et al. says that a family of SAPF controllers, which evaluates the compensation reference current using synchronous rotating frames, employs a structure based on Park's transformation: direct transform, lowpass filtering (LPF), and inverse transform[10]. Mohammad et al.'s paper deal with the design of a novel SRF method that can extract the reference compensating current for single-phase SAPF. Unlike previous SRF studies, the proposed method has an innovative feature that does not require a fictitious current signal and it includes frequency-independent operation, accurate reference current extraction, and relatively fast transient response[11]. In a paper by Kalpesh and Suhas, shunt active filter is designed with SRF algorithm to compensate the harmonic current of a three phase Non- Linear load. In these, load current, DC bus voltage $\&$ source voltage are sensed to compute the reference current of shunt active power filter. Driving signal for shunt active filter are produced by feeding reference by feeding reference \& actual Output current to hysteresis band current controller[12]. Rejil et al. presented a simple paper that illustrates the working of SAPF using SRF control strategy. A three phase current controlled VSI with a DC link capacitor across it is used as an active filter. SRF algorithm is used to extract the harmonic components. Hysteresis band current control (HBCC) technique is used for the generation of firing pulses to the inverter[13]. In a paper by Vikas et al. control schemes for shunt active power filter using perfect harmonic cancellation (PHC) and synchronous reference frame (SRF) methods as reference current generation techniques are proposed. In PHC method reference signals are calculated using positive sequence component of voltages taken from PCC and in SRF method reference signals are transformed from three-phase stationary frame (a-b-c) into three phase rotating frame (0-d-q)[14]. Diptimayee and Pravat used this theory in hybrid series active power filter for harmonic elimination in their work[51].

\section{B. DC link PI Control Theory}

Venkata et al. presented a paper whose main objective is the analysis and comparison of THD of the source current with different types of controllers and THD of source current with conventional PI controller is compared with the artificial neural network (ANN) based PI and Particle Swarm Optimization (PSO) based PI[15]. Parimala et al, presented a paper in which the PI controller is used to regulate the DC link voltage. The PWM controller is used to generate gate pulses and applied to three phase VSI based shunt active power filter with split capacitor topology[16]. Seemant and Seema have used indirect current control technique using PI controller in their work[17]. Arulkumar et al. presented a paper in which the proposed approach is only calculation of real power losses for extracting the three-phase reference currents for shunt active filters, evaluating their performance using a three phase, five level cascaded multilevel VSI based active filter with PI Controller in MATLAB[18]. Two different control methods has been proposed for SAPF based on proportional-integral (PI) controller and intelligent PIcontroller with ant colony optimization are presented in a paper by Brahim et al. [19]. In a paper by Akashkumar et al., the dynamic performance of the systems are Evaluated under different supply conditions and compared with the performances of the working with PI controller[20]. In 


\section{IJIREEICE \\ International Journal of Innovative Research in Electrical, Electronics, Instrumentation and Control Engineering \\ ISO 3297:2007 Certified \\ Vol. 5, Issue 1, January 2017}

Gowtham and shobha's paper, they have used a PI controller whose proportional and integral constants are being optimised using genetic and PSO algorithm[21]. In the same control strategy, PI controller was being replaced by fuzzy logic controller to improve the performance of system in a paper by Shuai Hao et al.[22]. In a paper by $\mathrm{Yu}$ Wang et al., the study investigates the inherent influence of a DC-link voltage controller on both DC-link voltage control and the compensation performance of a three-phase, four-wire SAPF[23]. Karuppannan and kamala kanta presented a paper in which proportional integral (PI) or fuzzy logic controller (FLC) is used to extract the required reference current from the distorted line-current, and this controls the DC-side capacitor voltage of the inverter. The shunt APF is implemented with PWM-current controlled VSI and the switching patterns are generated through a novel adaptive-fuzzy hysteresis current controller (A-F-HCC)[24]. Benchouia et al. presented a paper that shows simulation and experimental comparative study of sliding mode controller (SMC) and proportional integral (PI) regulator based the control of the DC bus voltage of three phase SAPF[25]. Paper by Kishore et al. presents simpler control logic. It is the cycle-by-cycle reference current control mode by regulating DC link voltage. The hardware PI and PLL based sine wave generator was used to implement control algorithm[26].

\section{Instantaneous Reactive Power Theory}

Pragathi and Bharthi presented a paper in which a shunt active power filter based on instantaneous power theory has been studied. The objective is to study different control strategies for real time compensating current harmonics at different load conditions[27]. Ramya et al. presented a paper which says that the control of shunt active power filter is not only compensating harmonics but also compensate reactive power[28]. Jagdish Kumar et al. focused on the fact that voltage source Inverter based SAPF is used for mitigation of harmonics and the DC link capacitor is used as energy source element connected across theSAPF. Instantaneous reactive power theory(IRP) is used to control the operation of shunt APF[29]. A paper by Moinuddin and Sanker Ram envisages on the simulation of instantaneous active and reactive theory based SAPF with MATLAB/ simulink, as a better solution for reduction of the harmonics[30]. Aruna Jyothi and Narsimham's paper says that IRP theory is used to identify the amount of compensating current injected into the network to compensate the reactive power required by non-linear loads and to bring the source current waveform as sinusoidal[31]. The instantaneous reactive power theory also known as p-q theory is used for most of the active power filters. SAPF for three phase three wire AC network is explained in a paper by Yogesh et al.[32]. In a paper by S Mikkili and A K Panda, control strategies for extracting the three-phase reference currents for shunt active power filters are compared, evaluating their performance under different source conditions with PI and fuzzy controllers[33, 40]. Mahni et al. presented a paper in which the work is to improve the quality of electric current in such networks. Four-wire shunt active filter is studied; different loads (balanced and unbalanced) are discussed[34]. Priya and Balu proposed a SAPF with IRP theory for its performance and ability to compensate the harmonics and reactive power [35]. Sujatha and Nagamalleshwar studied SAPF using IRP theory fed to induction drives[36]. Priyanka and Minal have used an improved method for harmonic mitigation in their SAPF using IRP theory system[37]. For fast feasible operation of SAPF, Liacheng $Z$ hu et al, used an improved instantaneous reactive power theory in their system[52].

\section{CONCLUSION}

Different control strategies for gate pulse generation in SAPF in recent years have been reviewed. These strategies were used to generate gate pulses for the IGBT/diodes of voltage source converter. The strategies were classified into three types viz, synchronous reference frame theory, DC link PI control theory and instantaneous p-q theory. Synchronous reference frame theory is utilized to extract the reference current from the distorted line current. The load currents are first converted in to $\alpha-\beta-0$ Coordinates using Clarke's Transformation and then in to $d-q-0$ rotating coordinating system using Park's Transformation. In DC link PI control theory the capacitor which is located on the DC bus of VSI is used as energy storage component for regulating voltage and delivering reactive power to the load. Instantaneous reactive power theory utilizes Clarke's transformation to find the reference current of SAPF. The effectiveness of active power filter depends on accurate extraction of fundamental component of current waveform and fastness of control strategy.

\section{ACKNOWLEDGEMENT}

The authors like to thank Bhilai Institute of Technology, Durg Chhattisgarh, India for providing the facilities to do the work and make it a success.

\section{REFERENCES}

[1]. Sangu Ravindra, Dr.V.C.Veera Reddy, Dr.S.Sivanagaraju, Design of Shunt Active Power Filter to eliminate the harmonic currents and to compensate the reactive power under distorted and or imbalanced source voltages in steady state, International Journal of Engineering Trends and Technology- Volume2 Issue3- 2011.

[2]. P.Anjalee umara, V.Sarayu, Y.Suribabu, G.Sambasiva Rao, Shunt Active Power Filter For Current Harmonic Cancellation, Proc. Of Int. Conf. On Control, Communication and Power Engineering 2010 .

[3]. K.Sarasvathi, R.Rajalakshmi, Performance Analysis Of Shunt Active Filter Using Different Controllers, International Journal of Engineering Trends and Technology (IJETT) - Volume4Issue5May 2013.

[4]. Consalva J. Msigwa, Beda J. Kundy and Bakari M.M. Mwinyiwiwa, Control Algorithm for Shunt Active Power Filter using Synchronous Reference Frame Theory, World Academy of Science, Engineering and Technology, International Journal of Electrical, Computer, Energetic, Electronic and Communication Engineering Vol:3, No:10, 2009. 


\section{International Journal of Innovative Research in Electrical, Electronics, Instrumentation and Control Engineering ISO 3297:2007 Certified \\ Vol. 5, Issue 1, January 2017}

[5]. Tapankumar Trivedia,, Chandrakishor Gupta, Rajendrasinh Jadeja, Pragnesh Bhatt, Mihir Chaudhari, Implementation of Synchronous Reference Frame Theory based Shunt Active Power Filter using DSP Controller, Alternative and Renewable Energy Quest in Architecture and Urbanism, Energy Procedia 00 (2016) 1-7, Elsevier publication.

[6]. M.Sunitha, B. N . Kartheek, Elimination of Harmonics Using Active Power Filter Based on DQ Reference Frame Theory, International Journal of Engineering Trends and Technology (IJETT) Volume4Issue4- April 2013.

[7]. Kakoli Bhattacharjee, Design And Simulation Of Synchronous Reference Frame Based Shunt Active Power Filter Using Simulink, National Conference On Challenges In Research \& Technology In The Coming Decades (CRT September 2013).

[8]. Elango Sundaram, Manikandan Venugopal, On design and implementation of three phase three level shunt active power filter for harmonic reduction using synchronous reference frame theory, Electrical Power and Energy Systems 81 (2016) 40-47, Elsevier publications.

[9]. Xiangshun Li, Hongliang He, Jianghua Lu and Zhiwei Liang, Modified Synchronous Reference Frame Method for Active Power Filter Under Asymmetric and Distorted Supply Voltages Condition, 2015 International Conference on Industrial Informatics-Computing Technology, Intelligent Technology, Industrial Information Integration.

[10]. Alberto Pigazo,Victor M. Moreno, and Emilio J. Estebanez, A Recursive Park Transformation to Improve the Performance of Synchronous Reference Frame Controllers in Shunt Active Power Filters, IEEE Transactions On Power Electronics, Vol. 24, No. 9 , September 2009.

11]. Mohammad Monfared, Saeed Golestan, and Josep M. Guerrero, A New Synchronous Reference Frame-Based Method for SinglePhase Shunt Active Power Filters, Journal of Power Electronics, Vol. 13, No. 4, July 2013.

[12]. Kalpesh L. Deshmukh, Suhas M. Shembekar, Performance of Shunt Active Power Filter based SRF Algorithm under Non Linear Load, International Journal of Engineering and Technical Research (IJETR) ISSN: 2321-0869, Volume-3, Issue-5, May 2015.

[13]. Rejil C, AnzariM and Arun Kumar R, Design and Simulation of Three Phase Shunt Active Power Filter Using SRF Theory, Advance in Electronic and Electric Engineering, ISSN 2231-1297, Volume 3, Number 6 (2013), pp. 651-660 Research India Publications.

[14]. Vikas S. Bhandare, Nilesh M. Chamat, Prof. S. P. Diwan, Control of Shunt Active Power Filter with PHC and SRF Methods for Compenasation of Source Current Harmonics along with Hardware Implementation of SRF Method, International Journal of Engineering Research \& Technology (IJERT) ISSN: 2278-0181, Vol. 3 Issue 5, May - 2014

[15]. B.Venkata siva, B.Mahesh babu, L. Ravi Srinivas, S.S.Tulasiram, Design of Shunt Active Power Filter for Improvement of Power Quality with Artificial Intelligence Techniques, International Journal of Advanced Research in Electrical, Electronics and Instrumentation Engineering Vol. 3, Issue 8, August 2014.

[16]. Parimala V, Ganeshkumar D, Benazir Hajira A, Harmonic Reduction Using Shunt Active Power Filter With PI Controller, International Journal of Scientific Engineering and Research (IJSER), Volume 2 Issue 4, April 2014.

[17]. Seemant Chourasiya, Seema Agarwal, A REVIEW: Control Techniques for Shunt Active Power Filter for Power Quality Improvement from Non-Linear Loads, International Electrical Engineering Journal (IEEJ) Vol. 6 (2015) No.10, pp. 2028-2032.

[18]. A.Arulkumar, Dr.N.RathinaPrabha, M.KalaRathi, PI Controller Based Shunt Active Power Filter with Cascaded Multilevel Inverter, International Journal of Innovative Research in Science, Engineering and Technology Volume 3, Special Issue 3, March 2014.

[19]. Brahim Berbaoui, Chellali Benachaiba, Mustapha Rahli, Hamza Tedjini, An efficient algorithm to tuning PI-controller parameters for shunt active power filter using ant colony optimization, Przeglad Elektrotechniczny R. 87 NR 6(06):140-145 - December 2011.
20]. Akashkumar Chavada, pushprajsinh Thakor, Bipinkumar Nanecha, Simulation And Analysis Of Shunt Active Power Filters, International Research Journal of Engineering and Technology (IRJET) Volume: 03 Issue: 05, May-2016.

[21]. Gowtham N, and Dr.Shobha Shankar, PI tuning of Shunt Active Filter using GA and PSO Algorithm, $20162^{\text {nd }}$ International Conference on Advances in Electrical, Electronics, Information, Communication and Bio-Informatics(AEEICB 16)

22]. Shuai Hao, Zhouxing Fu, Qingliang Wang, Jie Zheng, Minglu Zhang, A Novel Control Strategy for Shunt Active Power Filter under Nonlinear and Unbalanced Three Phase Load Conditions, 2016 International Symposium on Computer, Consumer and Control(IS3C).

23]. Yu Wang, YunXiang Xie , Xiang Liu, Analysis and Design of DClink Voltage Controller in Shunt Active Power Filter, Journal of Power Electronics. 2015. May, 15(3): 763774.

[24]. Karuppanan P, Kamala Kanta Mahapatra, PI and fuzzy logic controllers for shunt active power filter - A report, ISA Transactions Volume 51, Issue 1, January 2012, Pages 163-169, Elsevier publications

[25]. M.T Benchouiaa, I.Ghadbanea, A.Goleaa, K.Srairib, M.H Benbouzidc, Design and Implementation of Sliding Mode and PI Controllers based Control for Three Phase Shunt Active Power Filter, The International Conference on Technologies and Materials for Renewable Energy, Environment and Sustainability, TMREES14 Energy Procedia 50 ( 2014 ) 504 - 511, Elsevier Publications.

[26]. Kishore Kumar Pedapenki, S. P. Gupta, Mukesh Kumar Pathak, Shunt Active Power Filter with MATLAB and d'SPACE 1104 Verification, International Journal of Applied Engineering Research ISSN 0973-4562 Volume 11, Number 6 (2016) pp 4085-4090 Research India Publications.

[27]. B.Pragathi G.Bharathi, Control Of Shunt Active Filter Based On Instantaneous Power Theory, International Journal of Engineering Research \& Technology (IJERT) Vol. 1 Issue 6, August - 2012.

[28]. M.Ramya, M.Sathyapriya, A.Benazir Hajira, P.Kumar, Mitigation of Line Current Harmonics Using Shunt Active Filter With Instantaneous Real and Reactive Power Theory, IOSR Journal of Electrical and Electronics Engineering (IOSR-JEEE) Volume 9, Issue 2 Ver. II (Mar - Apr. 2014), PP 59-67.

[29]. S.Jagadish Kumar, P.Sangeetha, Chandragiri Radha Charan, Shunt Active Power Filter Control by Instantaneous Reactive Power Compensation, International conference on Signal Processing, Communication, Power and Embedded System (SCOPES)-2016.

[30]. Moinuddin K Syed, Dr. B V Sanker Ram, Instantaneous Power Theory Based Active Power Filter: A Matlab/ Simulink Approach, Journal of Theoretical and Applied Information Technology 2005 2008 JATIT.

31]. G. Aruna Jyothi, DR. P. V. R. L. Narasimham, Implementation of Instantaneous Reactive Power Theory for Current Harmonic Reduction and Reactive Power Compensation in Three Phase Four Wire Power System, IOSR Journal of Electrical and Electronics Engineering (IOSR-JEEE), Volume 10, Issue 1 Ver. II (Jan - Feb. 2015), PP 68-74.

[32]. Yogesh S. Prabhu, A. A. Dharme,D. B. Talange, A Three Phase Shunt Active Power Filter Based on Instantaneous Reactive Power Theory, 2014 Annual IEEE India Conference (INDICON).

[33]. Suresh Mikkili, Anup Kumar Panda, Instantaneous Active and Reactive Power and CurrentStrategies for Current Harmonics Cancellation in 3-ph 4-Wire SHAF with Both PI and Fuzzy Controllers, Energy and Power Engineering, 2011,Volume:3, Issue:3 , 285-298.

[34]. T. Mahni, M.T Benchouiaa, k. Srairib,A.Ghamrib A.Goleaa , Three-Phase For-Wire Shunt Active Filter With Unbalanced loads, The International Conference on Technologies and Materials for Renewable Energy, Environment and Sustainability, TMREES14, Energy Procedia 50 ( 2014 ) 528 - 535 Elsevier Publications.

[35]. M.S.Priya, Uthaya Suresh Balu, Simulation results of a shunt active power filter using $p-q$ Theory Power Components Calculations, International Journal of Advance Research in Computer Science and Management Studies, Volume 2, Issue 2, February 2014 


\section{IJIREEICE \\ International Journal of Innovative Research in Electrical, Electronics, Instrumentation and Control Engineering ISO 3297:2007 Certified \\ Vol. 5, Issue 1, January 2017}

[36]. Pabbisetty Sai Sujatha, D.S.Nagamalleswararao, Modeling \& Analysis of Shunt Active Power Filter Using IRP Theory Fed to Induction Drive, Int. Journal of Engineering Research and Applications Vol. 4, Issue 10( Part - 6), October 2014, pp.121-126.

[37]. Priyanka Zamade, Minal Tomar, Improved Methodology for Harmonics Reduction using Shunt Active Power Filter Based on p$q$ Theory, 2013 International Journal of Science and Research (IJSR) ISSN (Online): 2319-7064.

[38]. R.Zahira , A.Peer Fathima, A Technical Survey on Control Strategies of Active Filter for Harmonic Suppression, International Conference on Communication Technology and System Design 2011, Procedia Engineering 30 ( 2012 ) 686 - 693, Elsevier Publications.

[39]. S. Saad, L. Zellouma, Fuzzy logic controller for three-level shunt active filter compensating harmonics and reactive power, Electric Power Systems Research 79 (2009) 1337-1341, Elsevier Publications.

[40]. Anup Kumar Panda, Suresh Mikkili, FLC based shunt active filter $(p-q$ and $I d-I q)$ control strategies for mitigation of harmonics with different fuzzy MFs using MATLAB and real-time digital simulator, Electrical Power and Energy Systems 47 (2013) 313-336 Elsevier Publications.

[41]. M. R. Sindhu, Manjula G.Nair, T.N.P. Nambiar, Three Phase Autotuned Shunt Hybrid Filter for Harmonic and Reactive Power Compensation, SMART GRID Technologies, August 6-8, 2015, Procedia Technology 21 ( 2015 ) 482 - 489, Elsevier Publications.

[42]. Sushree Sangita Patnaik, Anup Kumar Panda, Real-time performance analysis and comparison of various control schemes for particle swarm optimization-based shunt active power filters, Electrical Power and Energy Systems 52 (2013) 185-197, Elsevier Publications.

[43]. S. Parthasarathy, S. Rahini , S.A. Karthick kumar, Performance Evaluation of Shunt Active Harmonic Filter Under Different Control Techniques, 2015 International Conference on Circuit, Power and Computing Technologies [ICCPCT] IEEE.

[44]. P.Bala Koteswara Rao 1, P.Esther Rani, Comparison of Shunt Active Power Filter with Different Control Algorithms Using Particle Swarm Optimization Technique, International Journal of Innovative Research in Science, Engineering and Technology Vol. 5, Issue 7, July 2016.

[45]. Sanjay Mathur, Niaz Kazmi, Talaha Chisti, Anurag Tripathi, A Review Of Control Strategies For Shunt Active Power Filter For Harmonics Compensation, International Journal of Scientific and Innovative Research 2015; Volume:3; Issue:1 ;Pages:55-60.

[46]. Satyaranjan Jena, Bhabasis Mohapatra,Chinmoy Kumar Panigrahi and Subodh Kumar Mohanty, Power Quality Improvement of 1- $\varphi$ Grid Integrated Pulse Width Modulated Voltage Source Inverter using Hysteresis Current Controller with Offset Band, 2016 3rd International Conference on Advanced Computing and Communication Systems (ICACCS -2016), Jan. 22 \& 23, 2016, Coimbatore, INDIA, IEEE.

[47]. Bipul Luitel, and Ganesh K. Venayagamoorthy, Differential Evolution Particle Swarm Optimization for Digital Filter Design, Evolutionary Computation, 2008. CEC 2008 (IEEE World Congress on Computational Intelligence). IEEE, September, 2008

[48]. Alok Kumar Dubey, Satya Prakash Dubey, Anurag Singh Tomar, Performance Analysis of PSO Based Hybrid Active Filter for Harmonic and Reactive Power Compensation under Non-ideal Mains, 2013 International Conference on Advanced Electronic Systems (ICAES), IEEE.

[49]. F.Krim, Parameter Estimation of Shunt Active Filter for Power Quality Improvement, IEEE The 5th International Power Engineering and Optimization Conference (PEOCO2011), Shah Alam, Selangor, Malaysia : 6-7 June 2011.

[50]. S. Musa, M.A.M. Radzi, H. Hisham, N.I. Abdulwahab, Fuzzy Logic Controller Based Three Phase Shunt Active Power Filter for Harmonics Reduction, 2014 IEEE Conference on Energy Conversion (CENCON).

[51]. Sushree Diptimayee Swain, Pravat Kumar Ray, Harmonic current and voltage compensation using HSAPF based on hybrid control approach for synchronous reference frame method, Electrical Power and Energy Systems 75 (2016) 83-90, Elsevier Publications. [52]. Liancheng Zhu, Jinchong Yan, Liang Chang, Fuyun Li, Yujie, Xioaying Su, Zhitao Wu and Di Cui, Reasearch on Shunt Active Power Filter based on Improved Instantaneous Reactive Power Theory, Intelligent Control and Information Processing (ICICIP), 2015 Sixth International Conference, IEEE. 